\title{
Activated Carbon Electrode From Desiccated Coconut Residue for High Performance of Supercapacitors
}

\author{
Mohd Adib Yahya ${ }^{1}$, Masbudi Baharuddin ${ }^{1}$, C. W. Z. C. W. $\operatorname{Ngah}^{1} \&$ M. A. Hashim ${ }^{1}$ \\ ${ }^{1}$ Faculty of Science and Technology, Universiti Sains Islam Malaysia (USIM), Malaysia \\ Correspondence: Mohd Adib Yahya, Faculty of Science and Technology, Universiti Sains Islam Malaysia (USIM), \\ Malaysia.E-mail: mohd.adib82@gmail.com
}

Received: February 26, 2015 Accepted: March 2, 2015 Online Published: March 6, 2015

doi:10.5539/jmsr.v4n2p45 URL: http://dx.doi.org/10.5539/jmsr.v4n2p45

\begin{abstract}
Supercapacitors with nanostructured activated carbon electrodes from natural precursors have sparked huge attention due to its great stability of cycle as well as low cost and excellent performance. In this study, activated carbon was produced from desiccated coconut residue by chemical activation with $\mathrm{KOH}$. The supercapacitor was characterized in a supercapacitor configuration by cyclic voltammetry and charge-discharge with potential window of $1 \mathrm{~V}$ and current loads of $1 \mathrm{~A} / \mathrm{g}$. Supercapacitor electrodes prepared from desiccated coconut residue exhibited excellent specific capacitance of $83 \mathrm{~F} / \mathrm{g}$.
\end{abstract}

Keywords: supercapacitor, activated carbon, desiccated coconut residue, cyclic voltammetry, charge discharge

\section{Introduction}

Electrical double layer capacitors (EDLCs) with activated carbon electrodes from natural precursors have attracted huge attention due to their cycle stability, low cost, and imposing performance. These ACs basically represent high specific surface area, high electrical conductivity, easy and environmental friendly production in huge quantities (Liu \& Pickup, 2008). In 1957, Becker had discovered a capacitor based on carbon material with high surface area as electrode and sulphuric acid as electrolyte (Kotz \& Carlen, 2000). It fills in the gap between batteries and conventional capacitors in terms of power and energy densities. Both batteries and fuel cells have high specific energy but low specific power while capacitors have high specific power and low specific energy (Kotz \& Carlen, 2000). Low specific energy can be improved by increasing the electrode capacitance or electrolyte voltage window. The electrode capacitance can be overcome by using high capacitance electrode materials whereas the electrolyte voltage can be improved by using non-aqueous electrolyte with larger window of electrochemical stability (Jampani et al., 2010). Hence, electrochemical capacitors may improve both devices by providing both high specific and energy density (Kotz \& Carlen, 2000 \& Jagadale et al., 2013). This study was aimed at introducing a supercapacitor derived from desiccated coconut residue (DCR) based activated carbon (AC) treated with potassium hydroxide $(\mathrm{KOH})$.

\section{Experimental}

The preparation of DCR-AC was based on our recent study (Yahya et al., 2015). A known amount of raw DCR was first carbonized into char under $\mathrm{N}_{2}$ flow and then treated with $\mathrm{KOH}$ for $1 \mathrm{~h}$ and dried at $105^{\circ} \mathrm{C}$ for overnight followed by heating it for $1 \mathrm{~h}$ under $\mathrm{N}_{2}$ flow. Out of nine samples, we selected the best DCR-AC in terms of specific surface area and porosity after examined by $\mathrm{N}_{2}$ adsorption at $77 \mathrm{~K}$ (Quantachrome, Autosorb 2). Scanning Electron Microscope/Energy Dispersive X-Ray (EDX) was performed on Hitachi SU 1510/Horiba Emax 450. X-Ray Diffraction (XRD) was performed with Bruker AXS Germany (D8 Advance).

DCR-AC with specific surface area of $823.81 \mathrm{~m}^{2} / \mathrm{g}$, pore volume of $0.50 \mathrm{~cm}^{3} / \mathrm{g}$ and porosity of $76 \%$ (Yahya et al., 2015) was used to cell fabrication. Electrode was prepared by mixing $85 \mathrm{wt} \%$ of DCR-AC, $10 \mathrm{wt} \%$ of carbon black (TIMCAL), and 5\% of polyvinylidene-flouride (Sigma-Aldrich) in 1-methyl-2-pyrrolidone (Merck, Germany) to form slurry. The mixtures were then poured into an aluminium foil with thickness of $2.5 \mu \mathrm{m}$ using Elcometer Film Applicator. It was then dried in an oven for overnight at $120^{\circ} \mathrm{C}$. A sandwich type cell was fabricated from two electrodes with similar weights with electrode area of $1 \mathrm{~cm}^{2}$ and separated by filter paper as a separator and an electrolyte $\left(1 \mathrm{M} \mathrm{Na}_{2} \mathrm{SO}_{4}\right)$. Capacitive performances were evaluated by cyclicvoltammetry $(\mathrm{CV})$ and galvanostatic charge-discharge cycles (CD). CV was measured at scan rates of 5, 20, 50 and $100 \mathrm{mV} / \mathrm{s}$. CD was measured with current load $1 \mathrm{~A} / \mathrm{g}$. 


\section{Results and Discussion}

\subsection{Physical Properties of DCR-AC}

Figure 1 shows the results of EDX analysis of the DCR-AC studies. It was observed that weight percentage (wt \%) of carbon was $85.24 \%$, followed by oxygen (12.93\%), Chlorine $(0.82 \%)$, Potassium $(0.56 \%)$ and Silica $(0.15 \%)$. Figure 2 shows the XRD spectra of DCR-AC. Result showed a turbostratic disordered carbon with low crystallinity between graphite and amorphous carbon. The peak at $26.3^{0}$ was related to gaphitic plane (Bhattacharjya \& Yu, 2014).
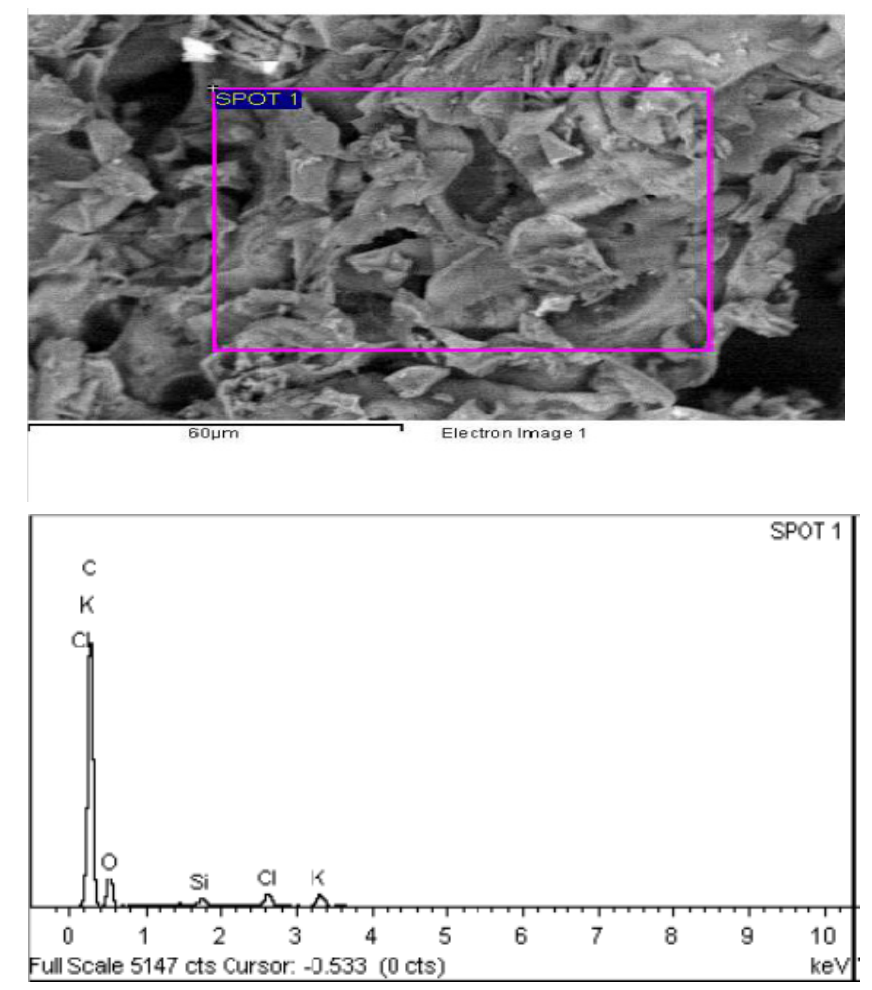

Figure 1. EDX analysis of DCR-AC

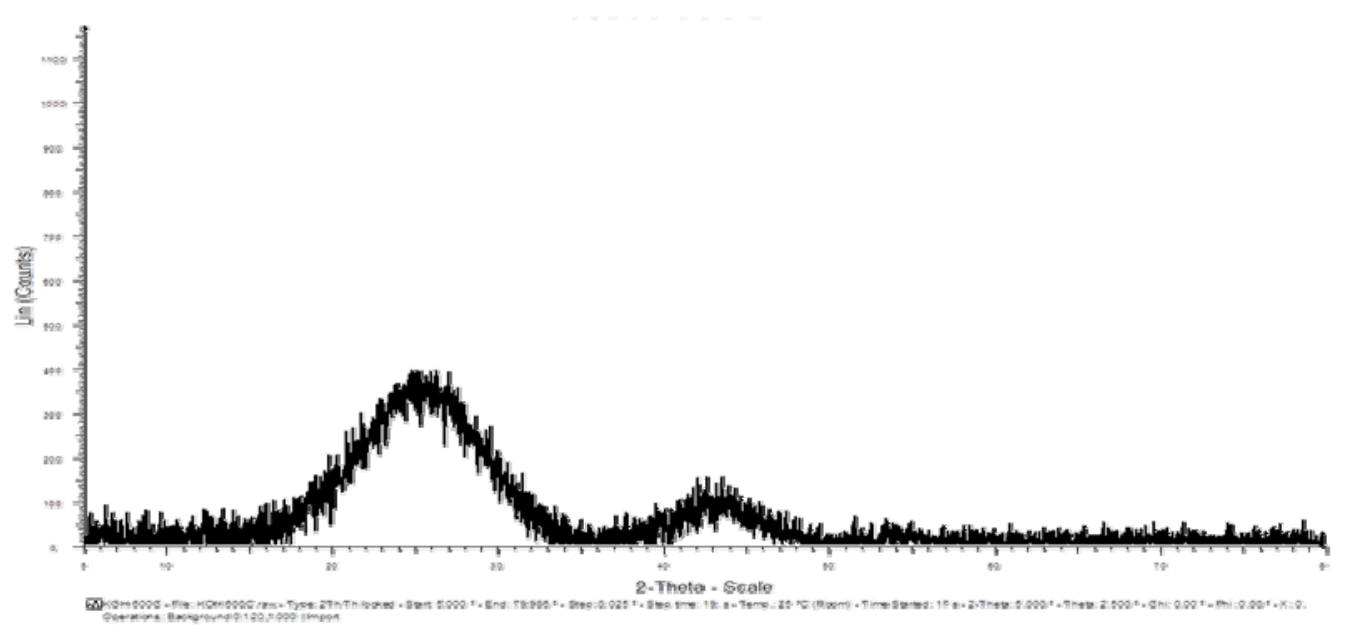

Figure 2. XRD analysis of DCR-AC 


\subsection{Electrochemical Behavior}

Figure 3 shows a cyclic voltammogram of the DCR-AC of the fabricated supercapacitor for all scan rates studied. It exhibits typical double-layer capacitive behaviour. It was also found that the cathodic and anodic charging currents increased with scan rates indicating that dependence of the capacitance on the scan rates and a pure capacitive behaviour (Cho et al., 2011). A high rate scan could stimulate large ohmic resistance distorting the CV loop hence resulted in a narrower loop with an oblique angle (Cheng et al., 2014). It was found that the specific capacitance at $100 \mathrm{mVs}^{-1}$ was found to be $41.04 \mathrm{~F} / \mathrm{g}$. Figure 4 shows the charge-discharge cycles of the DCR-AC supercapacitor at $1 \mathrm{~A} / \mathrm{g}$. Generally, a symmetrical triangle curve indicates a good reversibility, high electrochemical stability, and no redox phenomena during the charge-discharge process. The IR drops of DCR-AC shows a good linear relationship with current densities which indicated low equivalent resistant and ideal capacitive characteristics behaviour (Cheng et al., 2014). The specific capacitance was found to be $83 \mathrm{~F} / \mathrm{g}$.

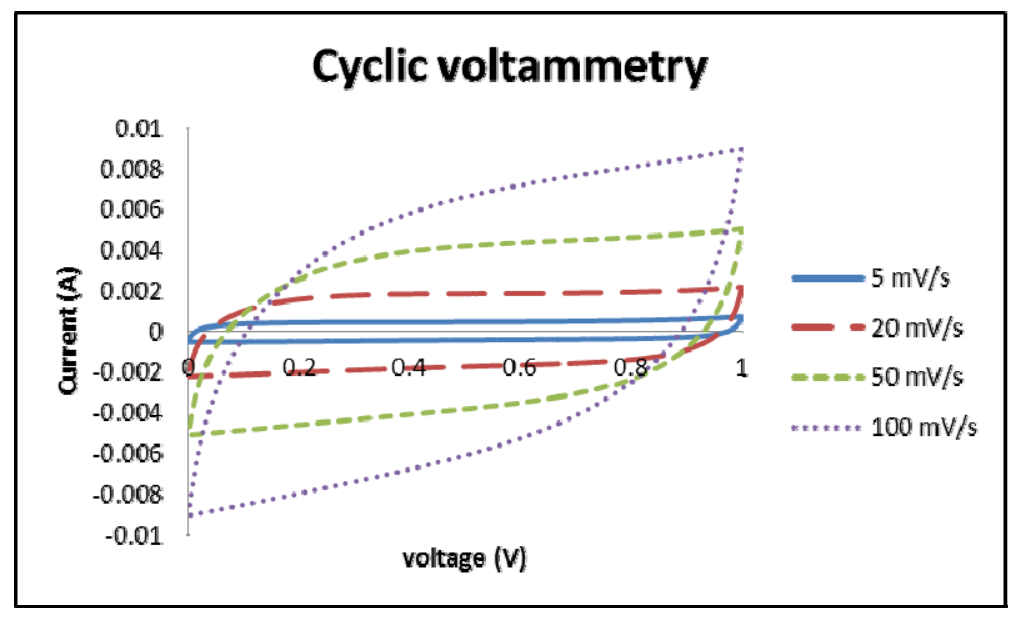

Figure 3. Cyclic voltammetry of desiccated coconut residue derived supercapacitor

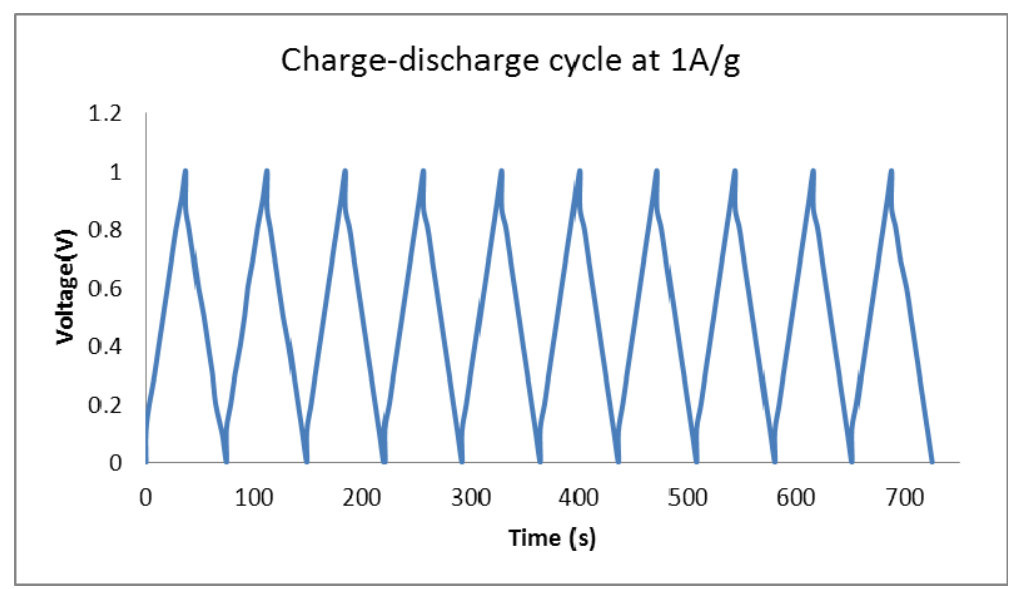

Figure 4. Charge discharge plot of supercapacitor with current load of $1 \mathrm{~A} / \mathrm{g}$

\section{Conclusion}

In this work, we have explored the capacitive performance of a newly precursor of desiccated coconut residue supercapacitor. The cell was fabricated by combination of 85:10:5 ratios of DCR-AC, carbon black, and pvdf. Results showed that the supercapacitor exhibited good performance with high specific capacitance.

\section{Acknowledgements}

The authors are grateful to University Sains Islam Malaysia and Ministry of Higher Education (MyBrain15) for findings of this project. 


\section{References}

Bhattacharjya, D., \& Yu, J. S. (2014). Activated carbon made from cow dung as electrode material for electrochemical double layer capacitor. Journal of Power Sources, 262, 224-231. http://dx.doi.org/10.1016/ j.jpowsour.2014.03.143

Cheng, L., Guo, P., Wang, R., Ming, L., Leng, F., Li, H., \& Zhao, X. S. (2014). Electrocapacitive properties of supercapacitors based on hierarchical porous carbons from chestnut shell. Colloids and Surface A: Physicochem. Eng. Aspects, 446, 127-133. http://dx.doi.org/10.1016/j.colsurfa.2014.01.057

Cho, W. J., Yeom, C. G., Kob, J. M., Lee, Y. M., Kim, S. H., Kim, K. M., \& Yu, K. H. (2011). Supercapacitive properties of carbon electrode in an electrolyte containing a newly synthesized two-cation salt. Journal of Electrochemical Science and Technology, 2(2), 63-67. http://dx.doi.org/10.5229/JECST.2011.2.2.063

Jagadale, A. D., Kumbhar, V. S., Dhawale, D. S., \& Lokhande, C. D. (2013). Performance evaluation of symmetric supercapacitor based on cobalt hydroxide $\left[\mathrm{Co}(\mathrm{OH})_{2}\right]$ thin film electrodes. Electrochimica Acta, 98, 32-38. http://dx.doi.org/10.1016/j.electacta.2013.02.094

Jampani, P., Manivannan, A., \& Kumta, P. N. (2010). Advancing the supercapacitors materials and technology frontier for improving power quality. The Electrochemical Society Interface, 57-62.

Kotz, R., \& Charlen, M., (2000). Principles and applications of electrochemical capacitors. Electrochimica Acta, 45, 2483-2498. http://dx.doi.org/10.1016/S0013-4686(00)00354-6

Liu, X., \& Pickup, P. G. (2008). Ru oxide supercapcitors with high loadings and high power and energy densities. Journal of Power Sources, 176, 410-416. http://dx.doi.org/10.1016/j.jpowsour.2007.10.076

Yahya, M. A., Al-Qodah, Z., Ngah, C.W.Z.C.W., \& Hashim, M. A. (2015). Preparation and characterization of activated carbon from Desiccated Coconut Residue by Potassium Hydroxide. Asian Journal of Chemistry, 27.

\section{Copyrights}

Copyright for this article is retained by the author(s), with first publication rights granted to the journal.

This is an open-access article distributed under the terms and conditions of the Creative Commons Attribution license (http://creativecommons.org/licenses/by/3.0/). 